\title{
¿Qué tan útil es la ooforectomía profiláctica?
}

\author{
William Onatra H.*; Gilberto Martinez M.**
}

\begin{abstract}
RESUMEN: Se revisa brevemente el comportamiento del ovario en diferentes etapas de la mujer y las complicaciones que presenta al practicar prematuramente la «ooforectomía profiláctica». Se sugiere preservar el ovario en mujeres pre y postmenopáusicas y en caso de extirpación prematura es necesaria la terapia de reemplazo hormonal.
\end{abstract}

SUMMARY: The ovarian behavior on women of different ages and its complications when "prophylactic ooforectomy" is done premature. Is suggested to preserve the ovary on pre-post menopausal women. In case of earlier extirpation a hormone replacement therapy is necesary.

\section{Embriología}

El desarrollo de la diferenciación gonadal se encuentra determinado genéticamente con base al cariotipo 46XX para la mujer y $46 X Y$ para el varón. Las células primordiales gonadales migran a través del saco vitelino para localizarse en la cresta gonadal (1) y el desarrollo de esta gónada pasa por 4 estadios: a) Gónada indiferenciada, donde estas células por mitosis en la semana 5-6 llegan a número de 100.000. b) Diferenciación y desarrollo de la cortical: este período está comprendido entre la 4-5 semana donde por factores genéticos, endocrinos, anatómicos los cordones medulares se disgregan para formar la porción medular del ovario. El epitelio superficial prolifera. c) Multiplicación de oogonias: entre la 6 y 7 semanas, una vez diferenciada la gónada, las oogonias se multiplican por división mitótica en estas primeras 20 semanas llegando a formar de 6 a 7 millones de células germinales. d) Formación del folículo: Las células superficiales se localizan alrededor de las oogonias formando así el primer folículo primordial (oocito detenido en profase de la primera división meiótica). En este período de dictioteno permanecen hasta la pubertad. Al nacimiento se encuentran entre 700.000 y 2'000.000 de células germinales (1).

Durante la pubertad las células germinales se reducen a 300.000 .

En la vida reproductiva se producen unas 400 ovulaciones y estas unidades declinan durante la menopausia para desaparecer en la senectud (2):

\section{Comportamiento del ovario durante la pre y postmenopausia}

Los estudios de Novak en 1965 (3) demostraron que el ovario mantenía su capacidad funcional varios años (más de 10) después del último período menstrual. Estudios posteriores de McNatty en el 79 (4), demostraron que todos los compartimentos intraováricos en la mujer joven eran activos, con producción de estrógenos, progesterona y andrógenos, con muy poca actividad celular en el estroma, a diferencia del ovario postmenopáusico que acusa un aumento de la actividad celular estromal con hipertrofia. La evaluación endocrina llevada a cabo por Dennefors en 1980 demostraron que en ovarios postmenopáusicos estimulados con gonadotrofinas se presenta un aumento de D-4-Androstendiona (D4A), estradiol (E2) y progesterona en la cortical y de D4A y E2 en la región estromal (5). Un estudio hecho por Mikhail (6) en ovarios postmenopáusicos de pacientes histerectomizadas encuentra en la vena ovárica un aumento de la dehidroepiandrosterona y estrona (E1).

\section{Función ovárica posthisterectomía}

Se acepta que la función ovárica no debe modificarse después de practicar histerectomía abdominal, sinembargo los primeros estudios hechos por Ranney en 77 (7) demuestran que el $50 \%$ de las pacientes acusan una disminución de su función. Estudios recientes confirman esta hipótesis y se plantea que pueden existir factores como: a) Disminución de las prostaglandinas de origen uterino, b) Pérdida del reflejo cérvix-hipotálamo-hipófisis (encontrado en animales inferiores). c). Una sustancia « $x »$ que modularía la vía útero-ovárica (8), podrían disminuir su función.

\section{Endocrinología post ooforectomía}

Una vez extirpados los ovarios, los niveles de gonadotropinas inician un aumento progresivo demostrable después de 3 semanas, los niveles de E2 caen así como los D4A y de estrona. Este estado de hipergonadismo hipogonadotropo presenta manifestaciones clásicas de oleadas de calor, insomnio, irritabilidad, piel seca,

* Profesor Asistente.Unidad de Endocrinología Ginecológica. Departamento de Obstetricia y Ginecología. Universidad Nacional de Colombia. I.M.I. Bogotá.

** Jefe departamento de Obstetricia y Ginecología, Instituto Nacional de Cancerología. 
sequedad de mucosa, vagina y piel. Metabólicamente hay una disminución de la globulina transportadora afectando la tiroxina, la angiotensina-aldosterona y fibrinogeno. Disminuye la LDL, aumenta el colesterol, disminuyen los factores de coagulación II, VII, IX, y el punto más importante es el riesgo de osteoporosis (9). En estos casos se recomienda terapia de suplencia con estrógenos conjugados (0.625) por 2 días más medroxiprogesterona 10 mg por 10 días (a partir del día 16) en forma cíclica por 10-15 años.

\section{Epidemiología}

Ha sido controversia en las diferentes escuelas si el ovario debe extirparse cuando una paciente entre 40-50 años se somete a una histerectomía abdominal. Los defensores del procedimiento aducen la extirpación es una profilaxis para el cáncer de ovario. Diferentes estudios demuestran que la incidencia de esta neoplasia es del 4-5\% (10-11). En una investigación de cohortes realizada por Randall (11), sobre un total de 900 pacientes histerectomizada y un seguimiento de 20 años mostró un promedio de cáncer de $0.2 \%$, las que tenían ambos ovarios fue de $0.01 \%$ y las que tenían un solo ovario $0.3 \%$ (9). Llama la atención que 28 miembros de 16 familias con antecedentes de Ca. de ovario y a quienes se les practicó ooforectomía profiláctica, 3 presentaron carcinomatosis y los autores concluyen que debe haber una susceptibilidad genética que compromete a otros tejidos embriológicamente relacionados con el ovario (10). Por los datos anteriores se recomienda evaluar cada caso y en lo posible preservar el ovario en pacientes entre 40-55 años.

\section{BIBLIOGRAFIA}

1. Salder TW., Lagman. Embriología Médica. 5 Edit. Williams \& Wilkins. Baltimore 1986.

2. Speroff L. Clinical Ginecologic Endocrinology \& Infertility. 3 Edit. Williams \& Wilkins. 1983.

3. Novak ER., Goldber B. Enzyme histochemistry of the menopausal ovary associated with normal and abnormal endometrium. Am. J. Obstet. Gynecol. 1965; 93: 669.

4. McNatty KP., Makris A., DeGrazia C. The production of progesterone, androgens and estrogens by granulosa cells, theca tissue and stromal tissue by human ovaries in vitro. J. Clin. Endocrinol. Metab. 1979; 49: 687.

5. Dennefors B., Janson P. Steroid production and responsiveness to gonadotropin in isolated stromal tissue of human menopausal ovaries. Am. J. Obstet. Gynecol. 1980; 136: 997.
6. Mikhail G. Hormone secretion by human ovaries. Gynecol. Invest 1970; $1: 5$.

7. Ranney B. The future function and control of ovarian tissue which in retained in vivo during hystereftomy. Am. J. Obstet. Gynecol. 1977; 128: 626 .

8. Charbonnel B. Human cervical mucus contains large amounts of prostaglandins. Fertil Steril. 1982; 38: 109.

9. Garcia CR. Preservation of the ovary: a reevaluation. Fertil Steril. 1984; 42: 510 .

10. Tobachman JK. Intrabdominal carcinomatosis after prophylactic oophorectomy in ovarian cancer prone families. Lancet 1982; 2: 795.

11. Randall CL. Ovarian Conservation. In progress in Gynecology. Edited by JV Meigs, Grune \& Sttratton. 1963. 